This is the post-print version of the final paper published in Fuel. The published article is available at http://www.sciencedirect.com/science/article/pii/S0016236107002347. Changes resulting from the publishing process, such as peer review, editing, corrections, structural formatting, and other quality control mechanisms may not be reflected in this document. Changes may have been made to this work since it was submitted for publication. Copyright @ 2007 Elsevier B.V.

\title{
Effect of inlet valve timing and water blending on bioethanol HCCI combustion using forced induction and residual gas trapping
}

\author{
A. Megaritis ${ }^{1 *}$, D.Yap ${ }^{2}$, M.L. Wyszynski ${ }^{3}$
}

1. Mechanical Engineering, School of Engineering and Design, Brunel University, West London, Uxbridge UB8 3PH, UK.

2. Singapore Institute of Manufacturing Technology, 71 Nanyang Drive, Singapore 638075.

3. School of Engineering, Mechanical and Manufacturing Engineering, University of Birmingham, Birmingham B15 2TT, UK.

\begin{abstract}
It has been shown previously that applying forced induction to Homogeneous Charge Compression Ignition (HCCI) of bioethanol with residual gas trapping, results in a greatly extended load range compared to normal aspiration. However at very high boost pressures, very high cylinder pressure rise rates develop. The approach documented here explores two ways that might have an effect on combustion in order to lower the maximum pressure rise rates and further improve the emissions of oxides of nitrogen (NOx); inlet valve timing and water blending. It was found that there is an optimal inlet valve timing. When the timing is significantly advanced or retarded away from the optimal, the combustion phasing could be retarded for a given lambda (excess air ratio). However, it would result in higher loads and lower lambdas for a given boost pressure, with possibly higher NOx emissions. Increasing the water content in ethanol gave similar results as the non-optimal inlet valve timing.
\end{abstract}

Keywords: HCCI, Bioethanol, Valve Timing, Fuel Water Blending.

\footnotetext{
* Corresponding author. Tel.: +44 (0)1895 266682, Fax: +44 (0)1895 256392

Email address: thanos.megaritis@brunel.ac.uk
} 


\section{Introduction}

HCCI is the process in which a homogeneous mixture auto ignites through compression. HCCI engines can have efficiencies close to these of diesel engines, with low levels of emissions of oxides of nitrogen (NOx) and particulate matter (PM). In addition, HCCI engines have been shown to operate with a range of fuels, e.g. gasoline and natural gas $[1,2]$.

Bioethanol is considered by many (despite the existing debate and critics) as one of the most important alternatives to gasoline and diesel as it can offer substantial reductions in consumption of fossil fuels and emission of greenhouse gases. The authors have previously shown that it was possible to use bioethanol as a fuel for HCCI operation using a gasoline style engine in conjunction with negative valve overlap, up to 7.5 bar indicated mean effective pressure (IMEP) with forced induction [3], and 4.18 bar IMEP on natural aspiration with moderate intake heating [4]. However, as the engine load increases, the maximum cylinder pressure rise rates increase accordingly, resulting in excessive combustion noise.

Internal trapping of residual exhaust gas has been proposed as a viable method to raise in-cylinder temperatures for gasoline HCCI operation. As the residual rates increase, the in-cylinder charge temperature also increases, allowing compression ratios typically found in gasoline engines to be used. In addition, the trapped exhaust gas acts as a diluent $[13,15]$. However, engines employing residual gas trapping have a limited load range compared to spark ignition combustion operation, as shown by the authors previous work on bioethanol, where a maximum of only 4.18 bar IMEP was achieved at $1500 \mathrm{rpm}[4]$.

The requirements for dilution limit the maximum power density of HCCI engines as violent combustion occurs when the excess air ratio is reduced. As such, the maximum 
load achieved is dictated by the amount of air or EGR (exhaust gas recirculation) that can be inducted into the engine to provide dilution. Forced induction methods, such as supercharging, have been shown to be effective in raising the power density of HCCI engines [16].

However, at high boost pressures, both the maximum pressure rise rates and the incylinder pressures reach high levels. This can be reduced by retarding the combustion phasing and/or lowering the compression ratio of the engine.

This paper determines whether varying the inlet valve timing can reduce the maximum pressure rise rates as it has been shown in previous work by the authors that the inlet valve timing can have some effect on combustion phasing for bioethanol HCCI with residual gas trapping [4]. Furthermore, water addition, in the form of blending with the fuel, is also explored as it has been used successfully with diesel combustion [18]. Water blending was also considered worth testing because the removal of water for making neat ethanol requires a large part of the total energy required in the production of ethanol for standard spark ignition (SI) and diesel engine fuelling. Reduction of the energy required for ethanol processing by eliminating the water removal requirement would provide substantial energy savings.

\section{Experimental}

Engine setup. A modified Medusa single cylinder engine installed at the University of Birmingham was used to examine the effect of valve timing on engine load and residual gas trapping. The engine was coupled to a DC dynamometer which keeps the engine at a constant set speed. A summary of the engine specifications can be found in Table 1. 
A Kistler 6125A pressure transducer was fitted flush with the wall of the combustion chamber, connected via a Kistler 5011 charge amplifier to a National Instruments data acquisition board fitted in an IBM compatible PC. A shaft encoder was also used to provide crank angles. Software was developed in-house, in the LabVIEW programming environment, to record the in-cylinder pressure versus crank angle for 100 consecutive engine cycles, and to analyze the resulting data.

Valve timings, engine IMEP and pressure traces were recorded for calculation of trapped residual fractions. Carbon dioxide, carbon monoxide, unburned hydrocarbons, oxygen and NOx emissions were also recorded.

The intake pressure is given as boost pressure (gauge pressure). Air from a standalone compressor was used for forced induction and no external EGR was applied. The load was controlled via the boost pressure in steps of 0.4 bar, and varying fuelling during operation at that specific boost pressure. The maximum pressure was limited to 1.2 bar to keep mechanical stresses below the safety limit.

The intake temperature was measured in the intake ports approximately $70 \mathrm{~mm}$ from the intake valve seats and was slightly elevated at $40{ }^{\circ} \mathrm{C}$, to minimize the effect of the inlet temperature on combustion phasing and to assist homogenization of the charge in light of the increased amounts of fuel used. The slight intake temperature elevation was achieved by means of an electric air heater (with temperature control) installed in the intake duct. The heater was located upstream of both the fuel entry port and the EGR loop.

Fuelling was via a standard injector located close to the inlet port of the engine. Anhydrous bioethanol provided by Shell Global Solutions (UK) was used unless specified. 
Valve timing setup. Negative valve overlap was used to trap residual gases and the engine throttle was kept wide open throughout the tests. The inlet and exhaust valve were set manually with a vernier adjusted camshaft pulley before operation. The range was limited by the sweep of the verniers. Proprietary fixed duration low lift camshafts were used with negative valve overlap. This procedure allowed control of the amount of the residual gas trapped.

The valve timing parameters used in this paper are the maximum opening points (MOP) of the inlet and exhaust valves given as follows:

(1) The inlet valve MOP is given in crank angle degree (CAD) after the exhaust stroke top dead centre (TDC).

(2) The exhaust valve MOP is given in CAD before the exhaust stroke TDC.

Test conditions. The conditions that were used during testing are described in Table 2. Cases 1, 2 and 3 are with different inlet valve timings for a case with lower trapped residuals. Cases 4, 5 and 6 are for operation with higher trapped residuals, as an advanced exhaust valve MOP results in increased amounts of trapped residuals. This has been detailed in the authors' previous work [3, 4]. Cases 7 and 8 are with water addition for the load region where high pressure rise rates are typically seen. The water was blended with the fuel before the start of the test sets.

\section{Results and discussion}

\subsection{Effects of inlet valve events}

Figure 1 shows scatter plots of the maximum pressure rise rates for Cases 1 to 6 for the achieved range of load (includes varying combustion phasing hence the scatter). It can be seen that with varying inlet valve timing, there exists a potential for higher maximum pressure rise rates, exceeding the knock limit of 10 bar/CAD. This is 
especially true for Cases 1 and 3 where the maximum pressure rise rates can reach a maximum of 16 to $18 \mathrm{bar} / \mathrm{CAD}$ compared to Case 2, where the maximum is 14 bar/CAD. It appears that varying inlet valve events does not help in the reduction of the maximum pressure rise rates. For Cases 4, 5 and 6 they remain largely similar with a high peak at the higher load of 6.4 bar IMEP. However, it should be noted that this occurs at a higher load which would be logical.

One factor contributing to the increased maximum pressure rise can be seen in Figure 2 which shows the maximum possible lambda with varying boost pressures for the various test cases. As seen, with a significantly retarded or advanced inlet valve event, the maximum lambda achieved drops; the maximum appearing to be Cases 2 and 5. As shown previously by the authors, in the case of forced induction with residual gas trapping and without intake heating the combustion phasing is dependent on lambda. In order to have stable combustion, for the small range of phasing possible, this results in a small range of lambda allowable.

So as seen, with a decreased lambda region allowable for stable combustion, as in the cases with a retarded or advanced inlet valve event, there is a lower amount of dilution. With increasing amounts of fuel, resulting in decreasing amounts of dilution, the pressure rise rates increase due to faster combustion. Hence it appears that Cases 2 and 5 are optimal in terms of minimizing NOx emissions as the lambda region for stable combustion is highest.

Figure 3 shows the variation of maximum load (IMEP) versus inlet valve events for the various boost pressures. As supporting evidence, the maximum loads appear to be lowest around the valve timing used in the optimal cases, increasing when the valve timing is retarded or advanced from it. 
The combustion phasing is strongly dependent on the in-cylinder temperatures before ignition. With higher in-cylinder temperatures, the combustion phasing is more advanced and vice versa for a lower in-cylinder temperature. Residual gas trapping greatly increases the in-cylinder temperature as part of the exhaust gases mixes with the fresh charge. This affects the in-cylinder temperature before ignition for the next cycle.

This is the reason why with increased residuals as in Case 5, the lambda region where stable combustion can take place is higher than that of Case 2, due to the increase of the thermal energy in-cylinder. This increase in temperature allows for a lower combustion temperature caused by increased dilution, as a larger portion of the thermal energy is trapped in-cylinder. More dilution can be allowed in order to keep the combustion phasing similar.

Varying the inlet valve MOP varies the inlet valve opening and closing events, as the camshafts used are of fixed duration. Figure 4 shows the calculated apparent compression ratio of the engine from the crank volume at inlet valve closure (IVC). As shown, by varying the IVC the apparent compression ratio of the engine changes. There is a minimal change from $110 \mathrm{CAD}$ to about $140 \mathrm{CAD}$. However, as the inlet valve MOP goes towards $168 \mathrm{CAD}$, there is an increasing change in the compression ratio, due to the IVC occurring when the piston on the upstroke is accelerating. A higher compression ratio would result in a higher end gas temperature during compression before ignition at TDC and vice versa. This also creates late backflow. Late backflow occurs when the inlet valve is still open during the compression stroke of the piston.

If the inlet valve is too advanced, there is still a high cylinder pressure when the inlet valve opens due to the nature of residual gas trapping with negative valve overlap. This is because the inlet valve opening (IVO) is also varied as the inlet valve MOP varies, thus occurring much earlier. This would then result in the hot residual gases escaping 
from the cylinder into the inlet manifold, due to the pressure difference and cooling down. Zhao et al. termed this as early backflow [12].

As seen, both the early backflow and the reduction of apparent compression ratio reduce the in-cylinder temperatures before ignition. Therefore, in order to prevent over retarded combustion phasing, increased fuelling must be applied to raise the temperatures of the trapped residuals. The increased fuelling results in lower dilution amounts for a given boost pressure and this creates higher in-cylinder pressure rise rates and maximum pressures.

It can also be noted that early backflow caused by an early inlet valve opening does not appear to affect lambda as much as the late exhaust valve closure when the inlet valve MOP is at $168 \mathrm{CAD}$. However, the engine load with early backflow is still higher than for the optimal Cases 2 and 5. This is partly due to the increase in volumetric efficiency as the early backflow case has no late backflow while the optimal Cases 2 and 5 have a mix of both mechanisms. The early backflow is reinducted into the cylinder while the late backflow remains in the intake manifold for that cycle, thus reducing the volumetric efficiency.

In summary, there appears to be an optimal inlet valve timing in terms of maximizing dilution so that stable combustion takes place at higher lambdas. In this case, it appears to be test Cases 2 and 5. A significantly advanced or retarded inlet valve timing causes the allowed lambda for stable combustion to be reduced, where the air fuel ratio (AFR) becomes richer and so the dilution is decreased. Consequently, this means that for a specific lambda at a specific boost pressure, with a small variation in inlet valve timing off the optimal, it might be possible to retard combustion phasing as the required lambda region shifts towards richer AFRs. The reason being that it now requires a lower lambda for a specific combustion phasing at that given boost pressure. 
An example is given in Figure 5, where Cases 4 and 5 are compared at 0.8 bar boost pressure. The lines shown are for similar combustion phasing for the two cases and the numbers represent the $5 \%$ fuel burn points at these lambdas. The range of AFRs at which both cases overlap is indicated on the graph. It can be seen that for a given combustion phasing for Case 5, the lambda at which it happens corresponds to a retarded combustion phasing for Case 4 . For example, when Case 5 has a $5 \%$ burn point of -3 CAD TDC, if the valve timing was advanced to that of Case 4 , and lambda was kept the same, combustion phasing would now be about -1 CAD TDC, meaning that it has retarded by about 2 CAD.

Previous work by the authors has shown that the combustion phasing is dependent on lambda due to the nature of residual gas trapping. The inlet valve event can play a part in combustion phasing due to the manipulation of the residual gas temperature and the compression ratio. However, as also shown earlier, the use of a retarded or advanced inlet valve event for any extended period, other than to correct momentarily combustion phasing that is too advanced, will reduce the dilution levels compared to the optimal cases. This will then have significant effect on NOx emissions as discussed in the next section.

\subsection{NOx emissions}

With decreased dilution, the potential for NOx formation is higher. Figure 6 shows the NOx emissions for the various cases at optimal combustion phasing for minimum brake specific fuel consumption (BSFC) for the load range achieved. In Figure 6a, it can be seen that for the cases with lower amounts of trapped residuals, varying the inlet valve timing has a significantly detrimental impact on NOx emissions. They can increase by more than a factor of 10 . 
In Figure 6b, NOx emissions are still generally low with a high spike at the lower load range for Case 6. Varying inlet valve events appear to have less impact on NOx emissions for Cases 4, 5 and 6. This is due to the increased amounts of residuals and higher lambdas which prevent NOx formation. It can be seen that retarding the inlet valve might be beneficial if there is sufficient dilution at higher boost pressures, as in Case 6. The maximum achieved load is higher than that of the optimal Case 5 (6.4 bar compared to 5.8 bar), without an increase in NOx emissions. Although the lambda was lower than in Case 5, it appears that there is still sufficient dilution to prevent increases of NOx formation. However, the maximum pressure rise rate for this point was above $10 \mathrm{bar} / \mathrm{CAD}$ resulting in substantial combustion noise.

\subsection{Combustion efficiency}

One reason why retarded inlet valve timing might be considered at higher residual rates is the increase in combustion efficiency as seen in Figure 7. The combustion efficiency is given as the ratio of the cumulative heat added from combustion to the amount of energy provided from the fuel. This does not take into account energy wasted before TDC and hence it differs from engine thermal efficiency.

It can be seen that with the decrease in dilution, the combustion efficiency for Case 6 , with the retarded inlet valve timing, improves slightly compared to Case 5, indicating that more of the fuel energy is converted into combustion energy. The combustion efficiency has increased by $5 \%$ to $10 \%$. The authors have previously found that increasing residuals with forced induction lead to decreasing combustion efficiency due to the higher dilution (increased lambda). Hence, any event that leads to a decrease in lambda will lead to an increase in combustion efficiency. This event can either be via retarding the inlet valve timing or by reducing the trapped residuals. 


\subsection{Blending of bioethanol and water}

From the scatter plot of the maximum pressure rise rates shown in Figure 8, the maximum rates of pressure rise for the load range achieved are largely above 10bar/CAD for $20 \%$ water content in fuel. This creates excessive combustion noise and possibly damage to the engine over prolonged periods of operation. For $10 \%$ water content in fuel, the pressure rise rates have a similar range compared to that of Case 2 which is without water. Hence, it appears that increasing the water content in fuel is counterproductive for the reduction of pressure rise rates. It can also be noted that the effective load range is much reduced compared to that of Case 2 with even $10 \%$ water content.

The maximum lambda achieved with increasing water content in the fuel did not change considerably when a blend with $10 \%$ water content was used. However, increasing the water content to $20 \%$ resulted in a substantial decrease of the maximum lambda achieved (from 2 without water to approximately 1.2 with $20 \%$ water).

It appears that water addition has an adverse effect on the benefits obtained from residual gas trapping. This may be attributed to a decrease of the in-cylinder gas temperatures at IVC caused by the added water, resulting in lower in-cylinder temperatures at TDC. This then creates a need to increase fuelling in order to keep the combustion stable and as a result lambdas decrease with larger amounts of water.

The inlet temperature of $40{ }^{\circ} \mathrm{C}$ was most probably insufficient for the complete evaporation of the water contained in the fuel. Upon entry of the blend into the cylinder and mixing with the hot exhaust gases, the large latent heat of vaporization resulted in lower mixture temperatures at IVC. One possible reason for the tolerance of the lower levels of water content might be that at these levels the evaporation was sufficient. 
The method used here is in contrast to previous HCCI work where water has been used as a method of combustion control using direct injection of varying amounts of water [19]. In the present work, a fuel blend with a fixed water-to-fuel ratio is introduced in the port. In this way, it has been demonstrated that there is a small tolerance of the combustion process to water contained in the fuel, which can be present due to contamination etc. Higher intake temperatures might increase the tolerance to water due to increased evaporation. This is worth of further investigation since in the case of HCCI combustion there are no limitations related to slow flame propagation resulting from the presence of water as in SI engines.

\subsection{Combustion control}

From the authors' previous work as well as the work presented in this paper, it can be seen that boost pressures are the main form of load control. Lambda affects combustion phasing and inlet valve events (or other events which cool down gas temperatures during compression) decrease the required lambda for a given combustion phasing. Increasing residual gas levels increases the required lambda for a given combustion phasing due to the increase in thermal energy available in the cylinder.

A better description would probably be that with residual gas trapping there appear to be various parameters which make up a 'virtual' compression ratio, as shown in Figure 9, analogous to that in an engine without residual gas trapping. Factors such as trapping additional residual gases increase this 'virtual' compression ratio, while factors such as retarded inlet valve closing and water content in the fuel reduce the 'virtual' compression ratio.

A qualitative guide as to how various parameters affect combustion phasing and the load range in forced induction HCCI can be drawn up from the various parameters as 
shown in Table 3. The actions themselves are not totally independent as there will be always some interaction between the events. However, these show the possible control events with boost pressure, inlet valve and exhaust valve timing.

For example in order to increase the engine load, the boost pressure can be increased. This can be done in combination either with retarding the exhaust valve timing or varying the inlet valve timing. Retarding the exhaust valve timing will reduce the trapped residual amounts, allowing for a higher load for a given boost pressure. This would also increase the fuelling required for stable combustion due to the reduction of trapped residuals. Advancing the inlet valve would reduce the apparent compression ratio of the engine, resulting in lower lambda (higher fuelling rates) required to maintain stable combustion. Retarding the inlet valve event would reduce the residual gas temperature at IVC, which would also give a similar effect, albeit less dramatic.

It must be noted that in order to advance the combustion phasing for a given lambda, there appears to be only one possible control which is to trap more residuals, hence increasing the in-cylinder thermal energy (supplemented by a small increase in boost to compensate for the displaced air). Varying the inlet valve timing can only maximize the thermal energy of the trapped residuals from the previous cycle, of which there is only a finite amount. If another control method such as variable compression or intake heating is available to further increase in-cylinder temperatures during compression, then there would be two possible control methods for that case. Variable compression has been used previously with success in combustion control due to its fast response times.

\section{Conclusions}

This paper documents the effects of inlet valve events and water blending in the fuel in a bid to reduce the pressure rise rates during HCCI combustion with forced induction. 
The most important findings can be summarized as such:

1. A significantly retarded or advanced inlet valve event decreases the required lambda for stable combustion compared to the optimal timing, resulting in potentially higher NOx emissions due to the lower dilution amount present.

2. A significantly retarded or advanced inlet valve event can retard combustion phasing that has become too advanced. However, it should be employed momentarily as it leads to higher NOx emissions. It can only retard combustion phasing, requiring a separate control method in order to advance combustion phasing.

3. Low concentrations of water in the fuel appear to have minimal effect on combustion. However, increasing the water content to $20 \%$ drastically reduces the available load range and lambda required for combustion. The decreased lambda results in substantially higher maximum cylinder pressure rise rates. Increased intake heating might increase the tolerance to water contained in the fuel.

4. Non-optimal valve timing and water contained in the fuel decrease the in-cylinder temperature during compression either by reducing the apparent compression ratio or by reducing the gas temperature at IVC. This retards the combustion phasing for a given lambda. Therefore, in order to maintain stable combustion, the lambda must be decreased, thus lowering the dilution levels and resulting in higher maximum cylinder pressure rise rates and NOx emissions.

5. The load control during forced induction is determined largely by the boost pressure. Inlet valve events can decrease lambda for a given combustion phasing, translating into a slightly higher load and higher NOx emission for a given boost pressure. Exhaust valve events can increase lambda for a given combustion 
phasing, translating into a slightly lower load and lower NOx emission for a given boost pressure.

6. At certain operating conditions it might be of advantage to decrease the lambda in order to improve the combustion efficiency, providing NOx emissions remain low enough.

\section{References}

[1] Christensen M., Johansson B., Einewall P. Homogeneous charge compression ignition (HCCI) using iso-octane, ethanol and natural gas - a comparison with spark ignition operation. SAE Paper No. 972824, 1997.

[2] Christensen M., Hultqvist A., Johansson B. Demonstrating the multi fuel capability of a homogenous charge compression ignition engine with variable compression ratio. SAE Paper No. 1999-01-3679, 1999.

[3] Yap D., Megaritis A. Applying Forced Induction to Bioethanol HCCI Operation with Residual Gas Trapping. Energy and Fuels 2005;19:1812-21.

[4] Yap D, Megaritis A, Wyszynski M.L. An Investigation into Bioethanol Homogeneous Charge Compression Ignition (HCCI) Engine Operation with Residual Gas Trapping. Energy and Fuels 2004;18:1315-23.

[5] Najt P.M. Foster D.E. Compression-ignited homogeneous charge combustion. SAE Paper No. 830264, 1983.

[6] Thring R.H. Homogeneous-charge compression-ignition (HCCI) engines. SAE Paper No. 892068, 1989.

[7] Ryan T.W., Callahan T. Homogeneous charge compression ignition of diesel fuel. SAE Paper No. 961160, 1996. 
[8] Gray A.W., Ryan T.W. Homogeneous charge compression ignition (HCCI) of diesel fuel. SAE Paper No. 971676, 1997.

[9] Nakano M., Mandokoro Y., Kubo S., Yamazaki S. Effects of exhaust gas recirculation in homogenous charge compression ignition engines. International Journal of Engine Research 2000;1:269-79.

[10] Lavy J., Dabadie J.C., Angelberger C., Wiland J., Juretzka A, Schaflein J., Ma T., Lendresse Y., Satre A., Schulz C., Kramer H., Zhao H., Damiano L. Innovative ultra-low NOx controlled auto-ignition combustion process for gasoline engines: the 4-SPACE project. SAE Paper No. 2000-01-1837, 2000.

[11] Oakley A., Zhao H., Ladommatos N. Experimental studies on controlled autoignition (CAI) combustion of gasoline in a 4-stroke engine. SAE Paper No. 200101-1030, 2001.

[12] Zhao H., Li J., Ma T., Ladommatos N. Performance and analysis of a 4-stroke multi-cylinder gasoline premixed charge compression ignited engine. SAE Paper No. 2001-01-0420, 2001.

[13] Zhao H., Peng Z., Williams J., Ladommatos N. Understanding the effects of recycled burnt gases on the controlled autoignition (CAI) combustion in fourstroke gasoline engines. SAE Paper No. 2001-01-3607, 2001.

[14] Li J., Zhao H., Ladommatos N. Research and development of controlled autoignition (CAI) combustion in a 4-stroke multi-cylinder gasoline engine. SAE Paper No. 2001-01-3608, 2001.

[15] Oakley A., Zhao H., Ma T., Ladommatos N. Dilution Effects on the controlled auto-iIgnition (CAI) combustion of hydrocarbon and alcohol fuels. SAE Paper No. 2001-01-3606, 2001. 
[16] Christensen M., Johansson B., AmnJus P., Mauss F. Supercharged homogenous charge compression ignition. SAE Paper No. 980787, 1998.

[17] Christensen M., Johansson B. Supercharged Homogeneous charge compression ignition (HCCI) with exhaust gas recirculation and pilot fuel. SAE Paper No. 2001-01-1835, 2001.

[18] Samec N., Kegl B., Dibble R. W. Numerical and experimental study of water/oil emulsified fuel combustion in a diesel engine. Fuel 2002;81:2035-44.

[19] Iwashiro Y., Tsurushim T., Nishijima Y., Asaumi Y., Aoyagi Y. Fuel consumption improvement and operation range expansion in HCCI by direct water injection. SAE Paper No. 2002-01-0105, 2002. 
Table 1. Engine specifications summary.

\begin{tabular}{ll}
\hline Engine type & Medusa single cylinder 4-valve engine \\
Bore & $80 \mathrm{~mm}$ \\
Stroke & $88.9 \mathrm{~mm}$ \\
Compression ratio & 12.5 \\
Fuelling type & liquid port-injected \\
\hline
\end{tabular}


Table 2. Test conditions.

\begin{tabular}{lcccc}
\hline Conditions & $\begin{array}{c}\text { Boost pressure } \\
\text { (bar g) }\end{array}$ & $\begin{array}{c}\text { Inlet valve } \\
\text { MOP (CAD) }\end{array}$ & $\begin{array}{c}\text { Exhaust valve } \\
\text { MOP (CAD) }\end{array}$ & $\begin{array}{c}\text { Fuel Water } \\
\text { content (\%) }\end{array}$ \\
\hline Case 1 & Up to 1.2 & 118 & 140 & 0 \\
Case 2 & Up to 1.2 & 144 & 140 & 0 \\
Case 3 & Up to 1.2 & 168 & 140 & 0 \\
Case 4 & Up to 1.2 & 118 & 168 & 0 \\
Case 5 & Up to 1.2 & 144 & 168 & 0 \\
Case 6 & Up to 1.2 & 168 & 168 & 10 \\
Case 7 & Up to 1.2 & 144 & 140 & 20 \\
Case 8 & Up to 1.2 & 144 & 140 & 0 \\
\hline
\end{tabular}


Table 3. Qualitative guide to combustion control with forced induction in-conjunction with residual gas trapping.

Actions possible

Requirements

Boost Inlet Valve Exhaust Valve

Higher load

Retard combustion

phasing for given

lambda

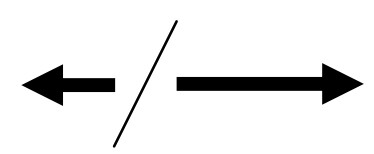

Advance combustion

phasing for given

lambda

$\longrightarrow$ represents retarding valve events, $\longleftarrow$ represents advancing valve events

Arrow lengths represent relative strengths 


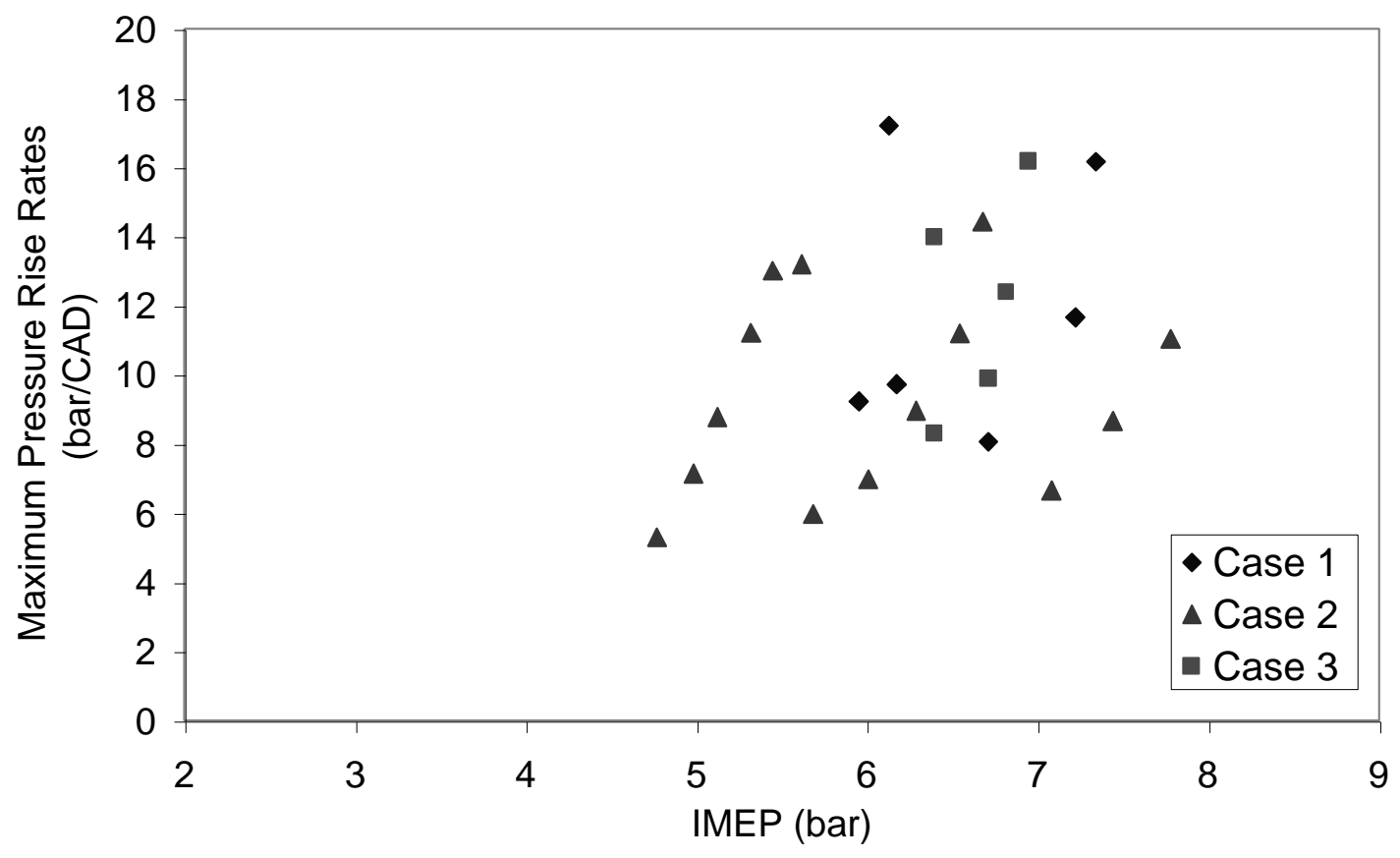

(a)

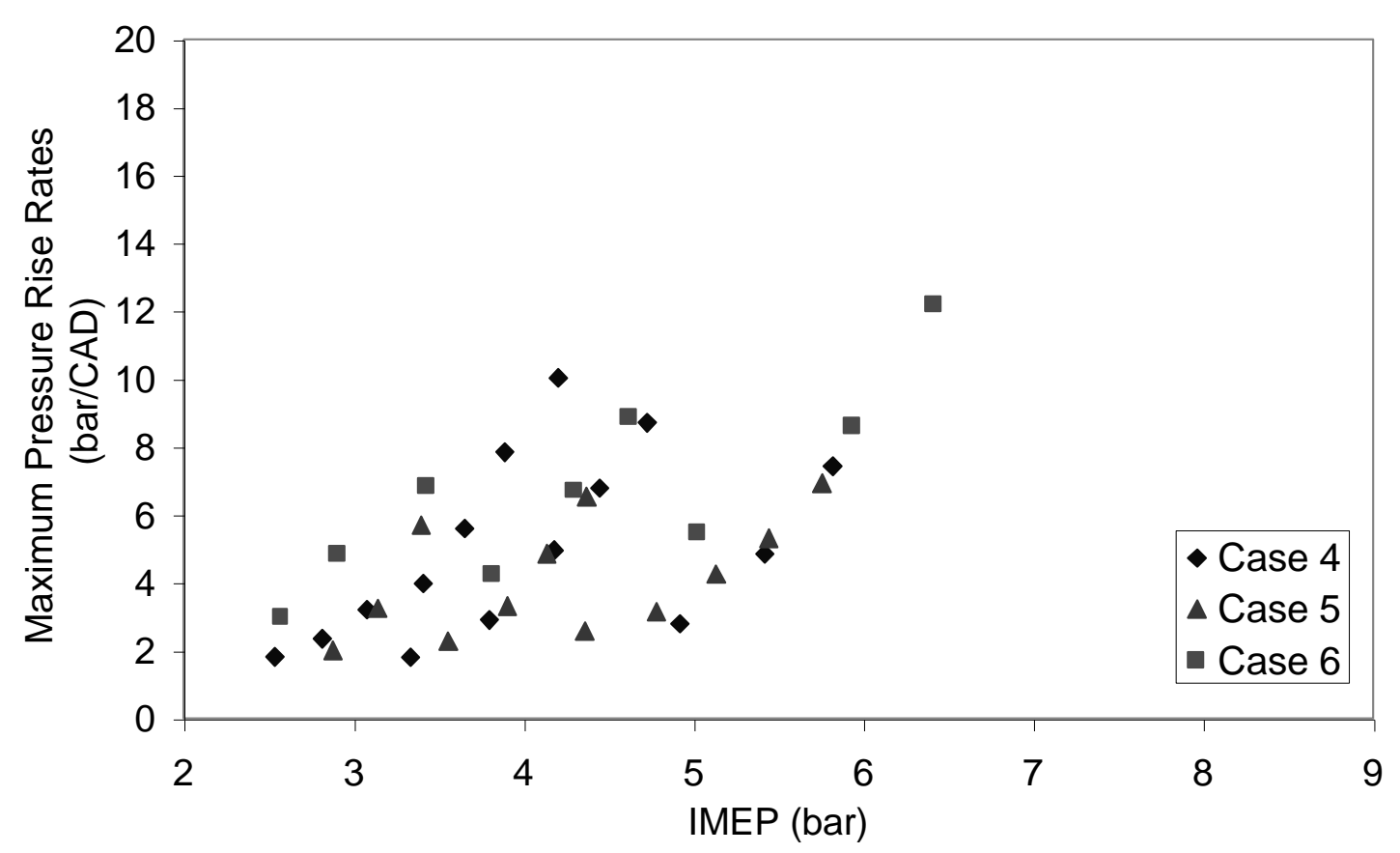

(b)

Figure 1. Maximum cylinder pressure rise rates versus load range: (a) Cases 1, 2 and 3, (b) Cases 4, 5 and 6. 


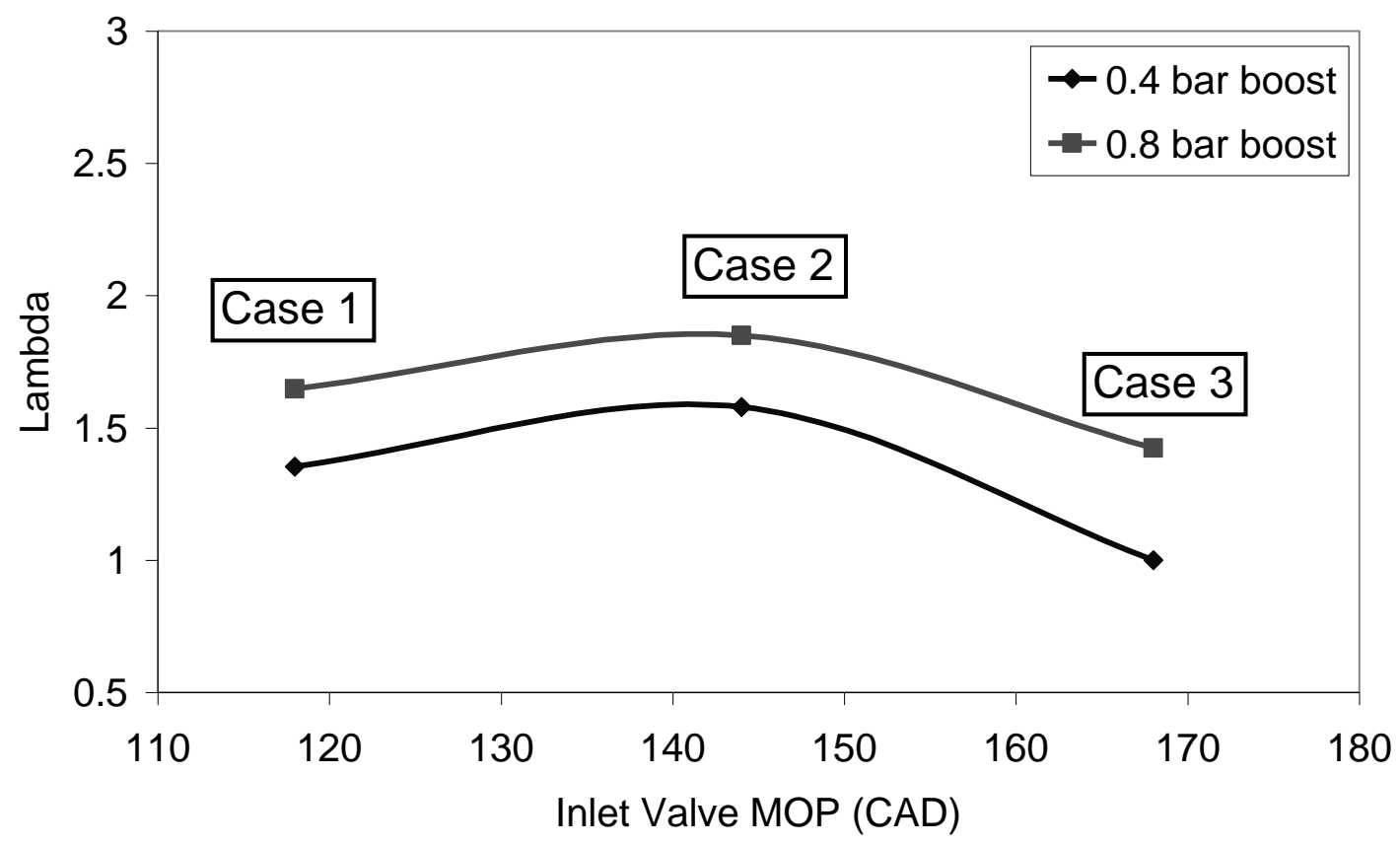

(a)

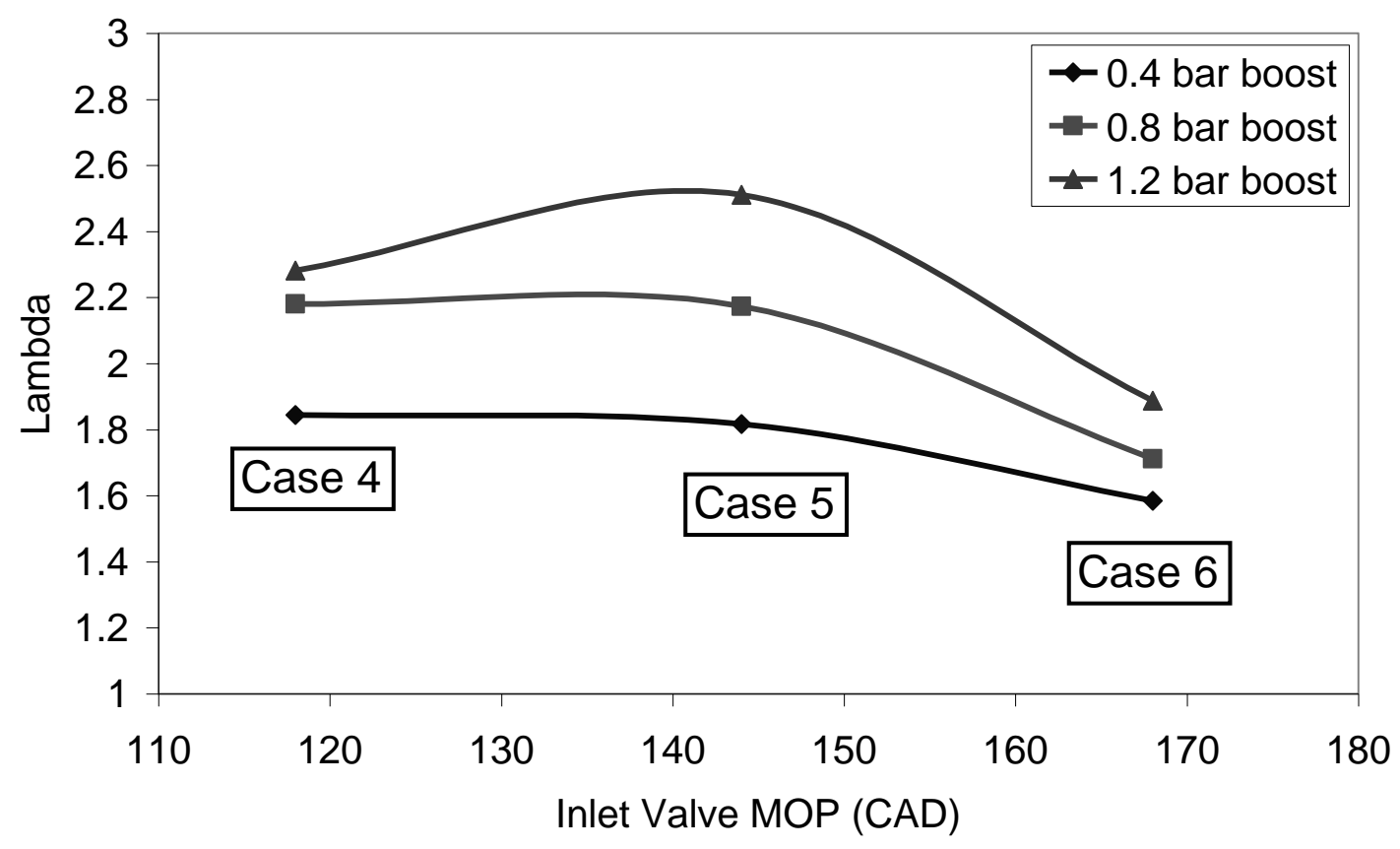

(b)

Figure 2. Variation of maximum lambda achieved with varying inlet valve timing: (a) Cases 1, 2 and 3, (b) Cases 4, 5 and 6. 


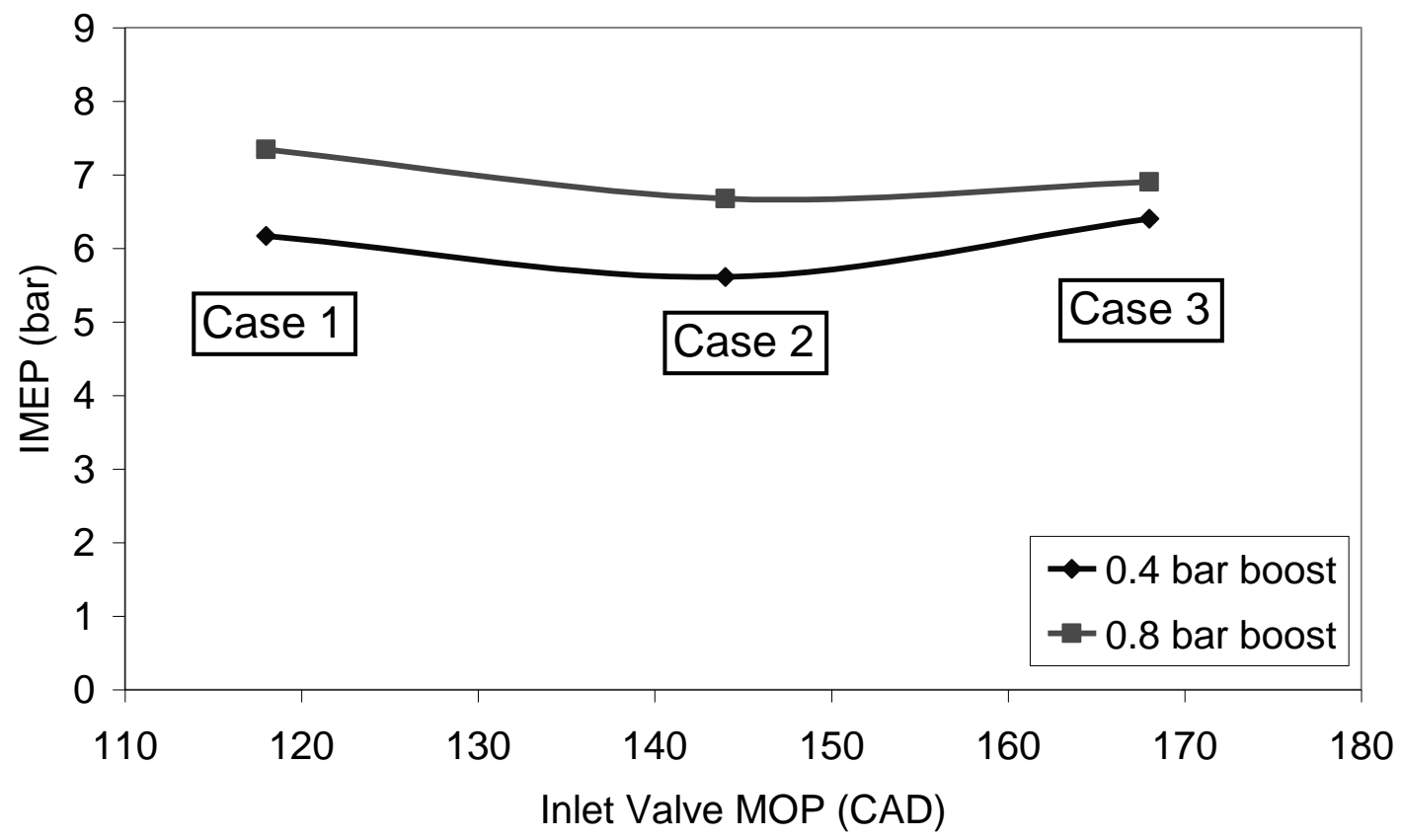

(a)

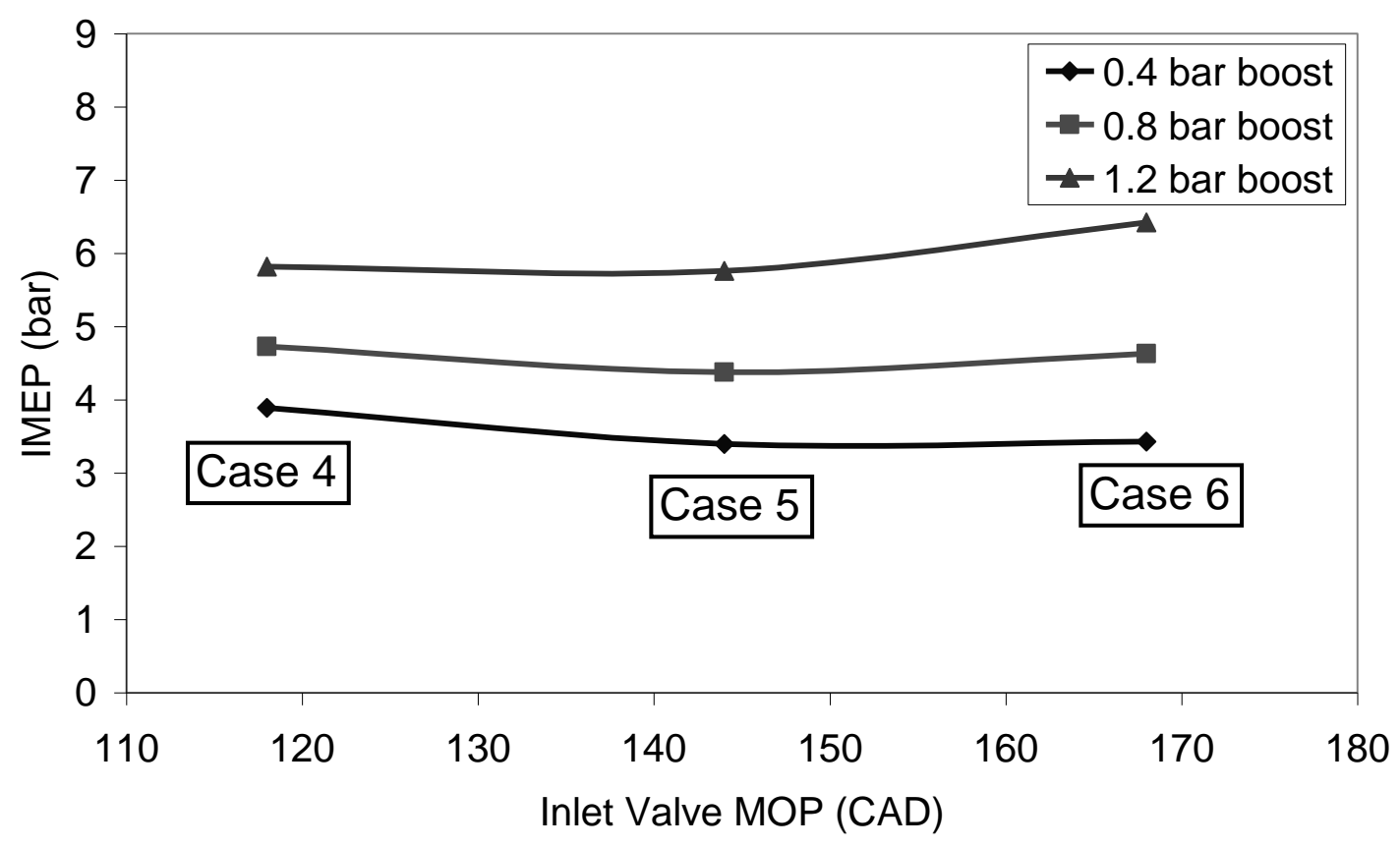

(b)

Figure 3. Variation of maximum load achieved with varying inlet valve timing: (a) Cases 1, 2 and 3, (b) Cases 4, 5 and 6. 


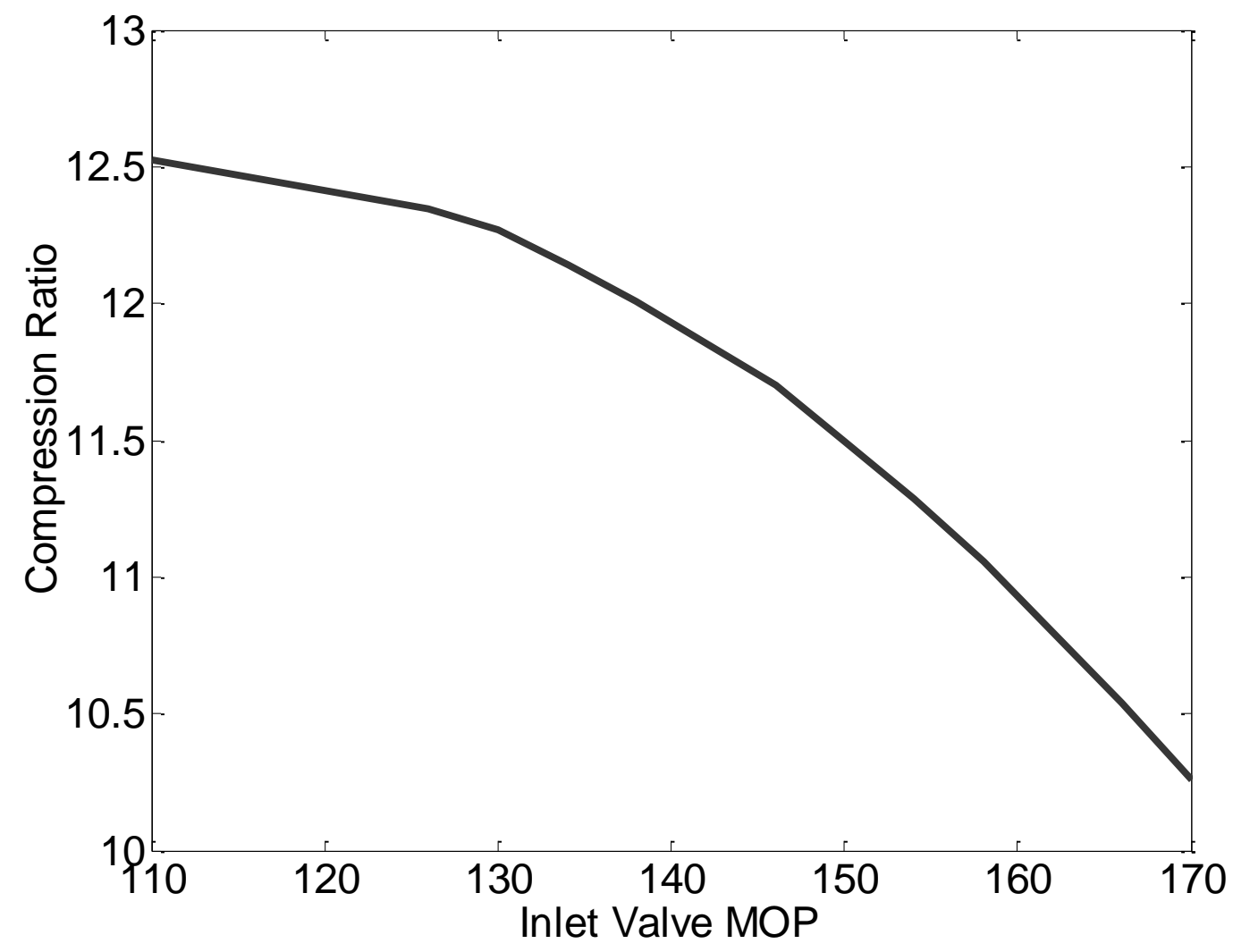

Figure 4. Change in compression ratio with varying inlet valve timing. 


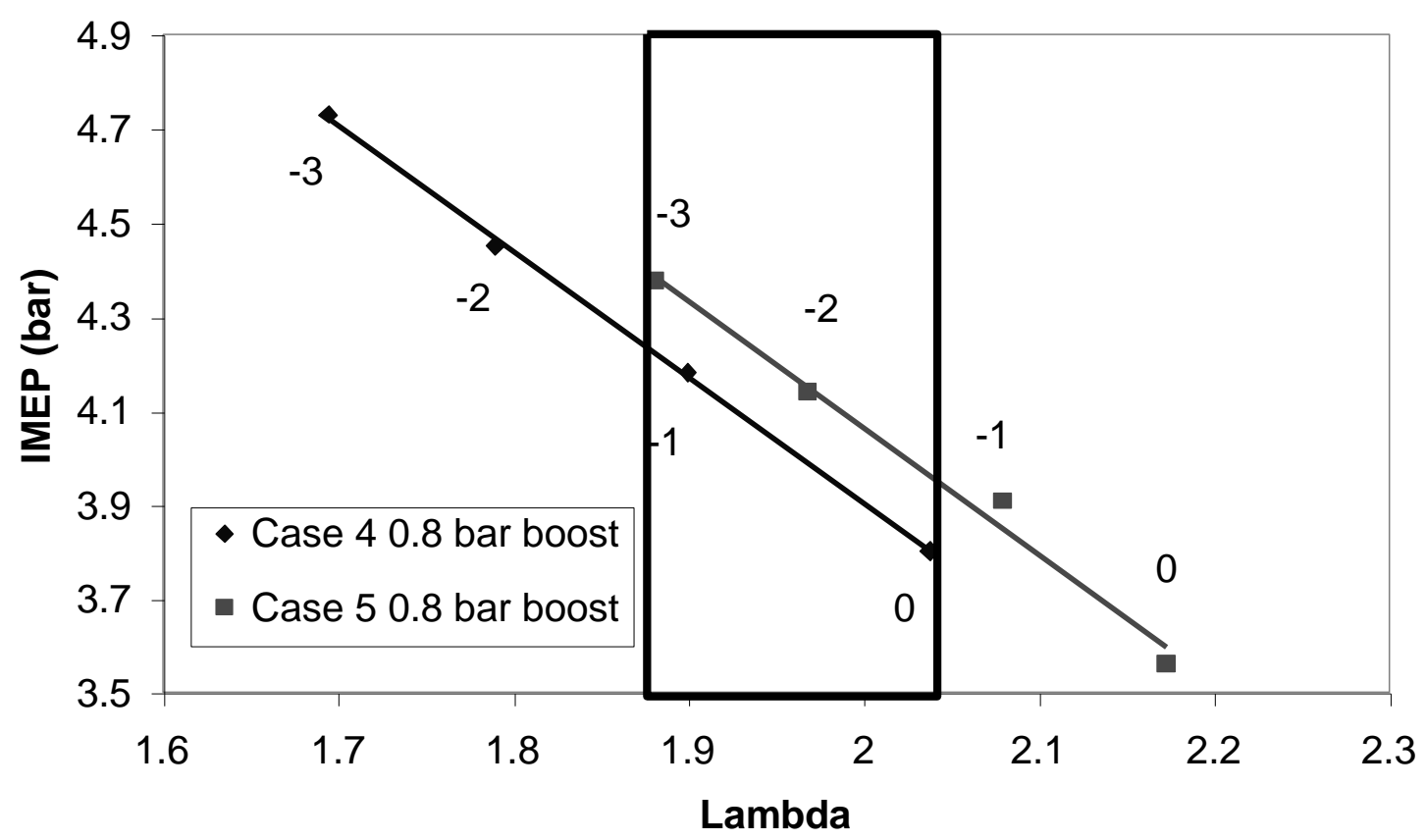

Figure 5. Change in combustion phasing and lambda for Cases 4 and 5. 


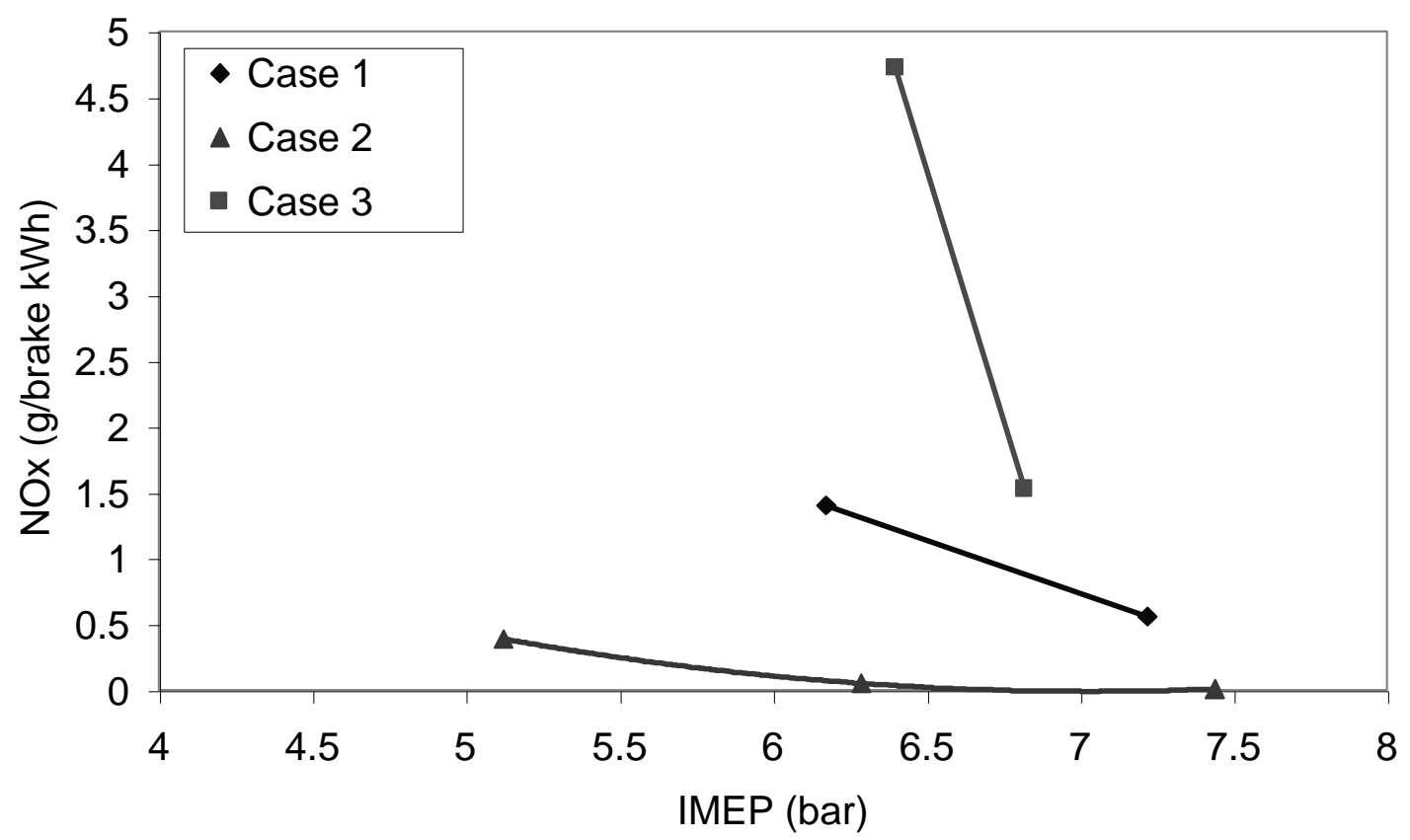

(a)

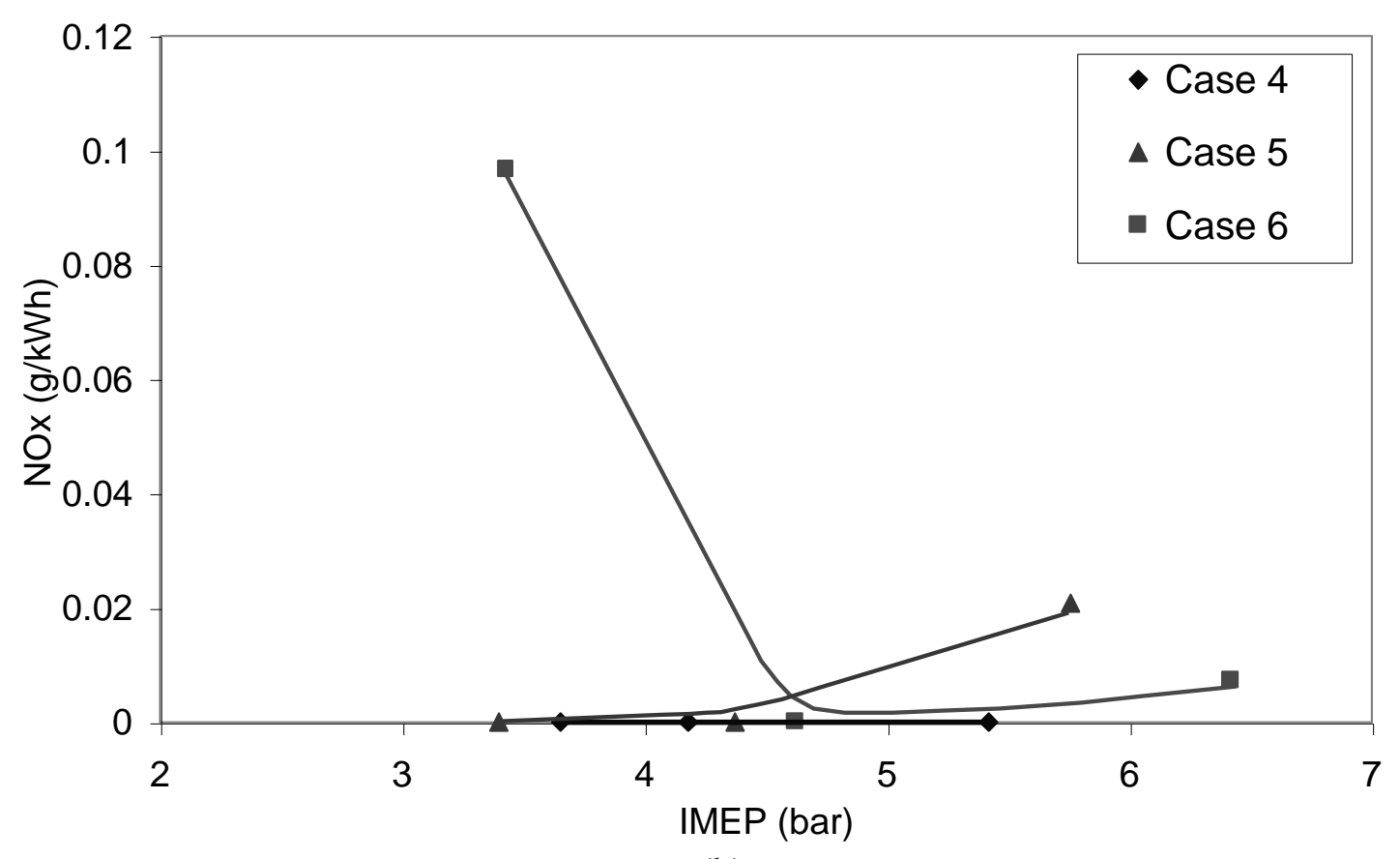

(b)

Figure 6. NOx emissions at optimal combustion phasing: (a) Cases 1, 2 and 3, (b) Cases 4,5 and 6. 


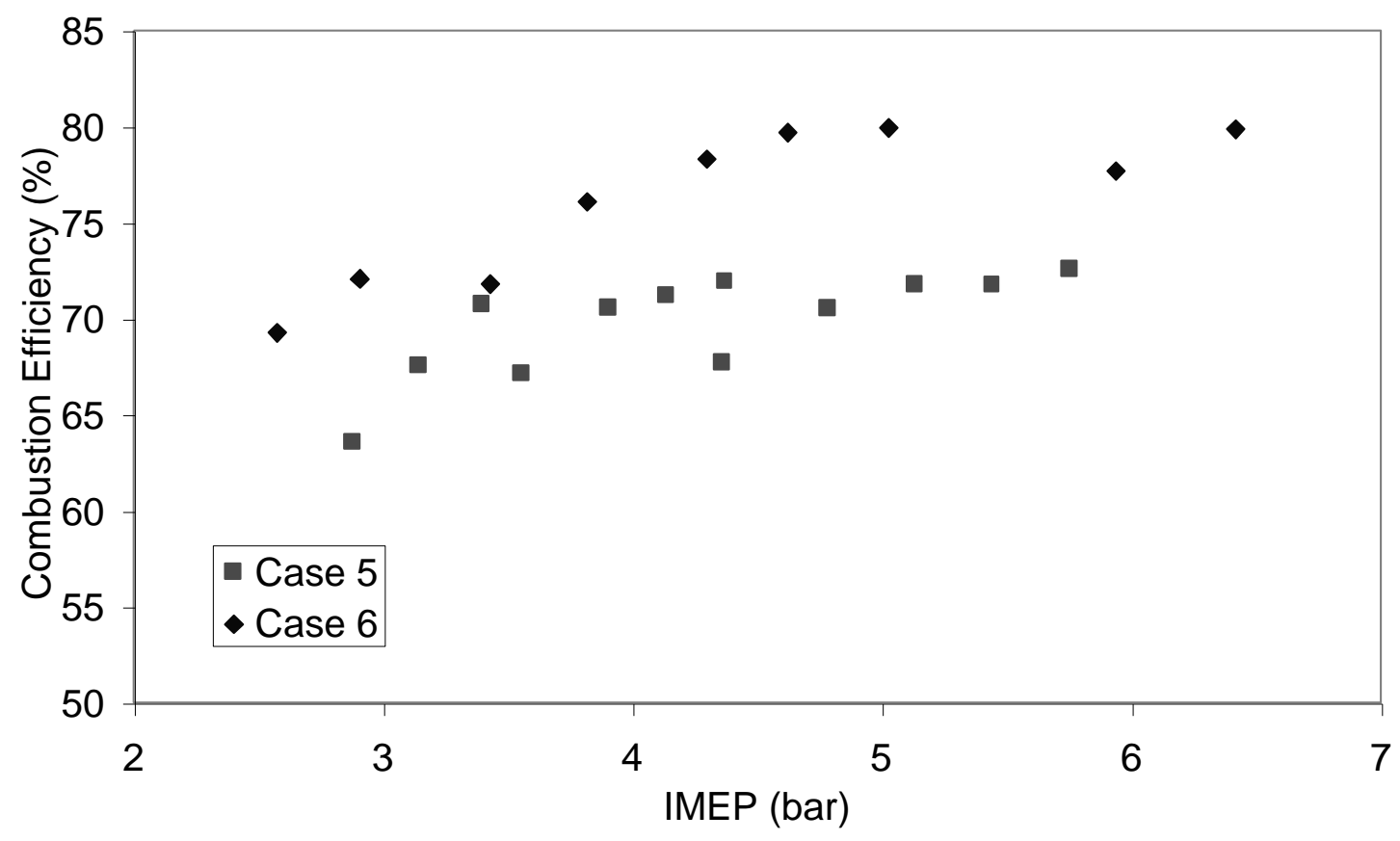

Figure 7. Combustion efficiency versus load range for Cases 5 and 6. 


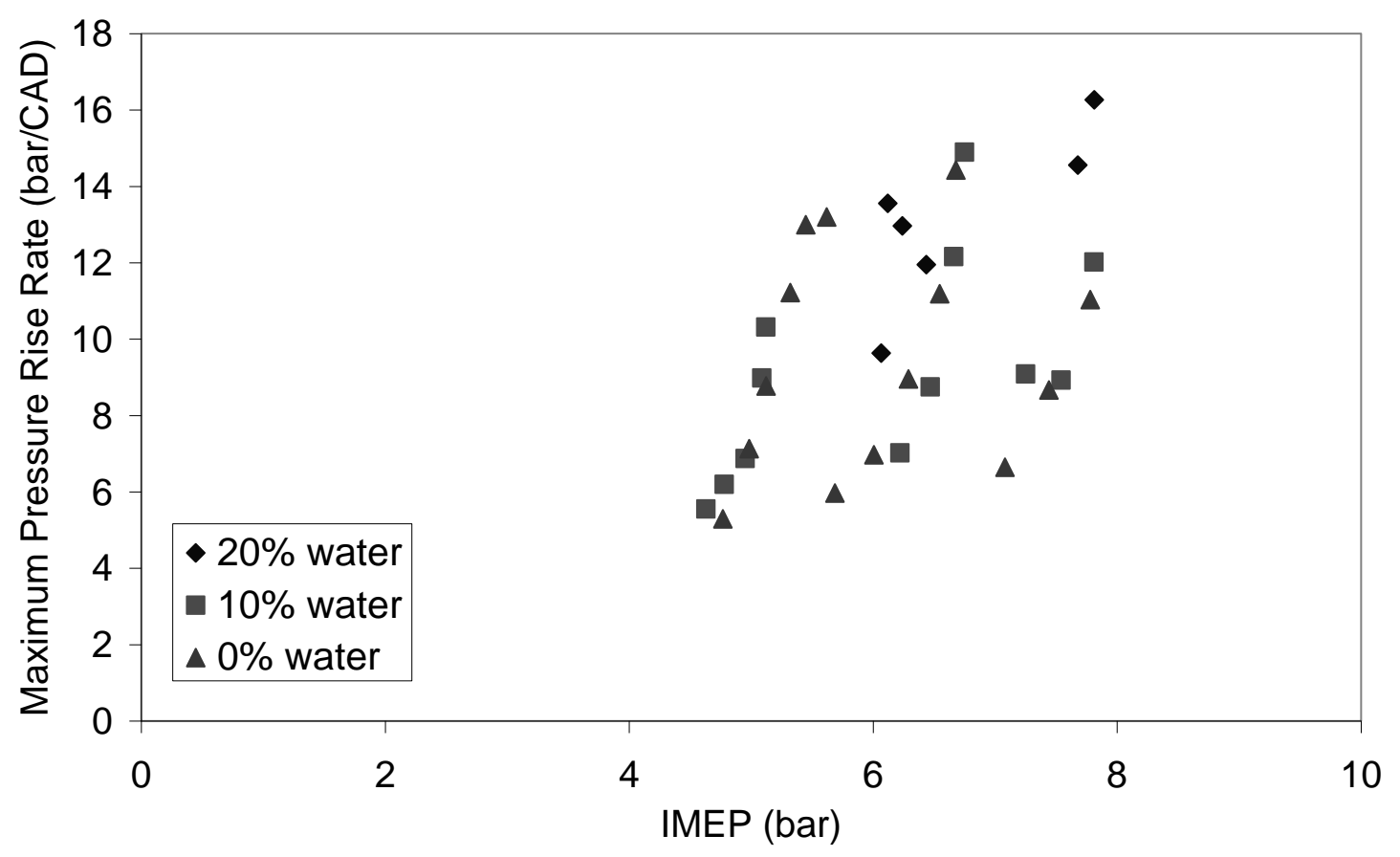

Figure 8. Maximum cylinder pressure rise rates for increasing fuel water content versus load range. 


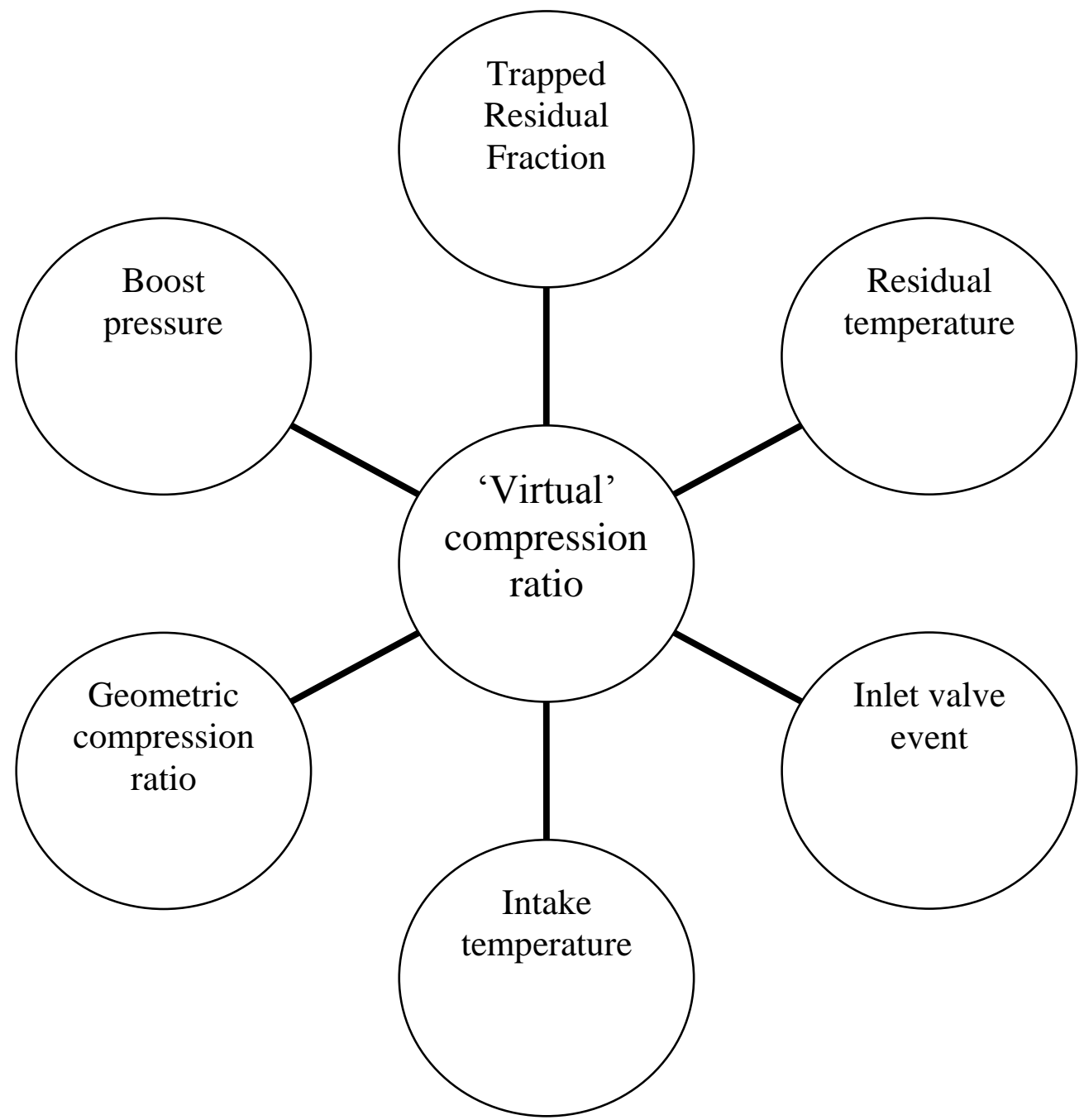

Figure 9. Factors contributing to the 'virtual' compression ratio. 